\title{
Scientist, businessman, visionary institution builder
}

\author{
E. V. Chitnis* \\ Varsha Vasant Vihar, Lane-2, Plot 71, Anand Park, Aundh, Pune 411 007, India
}

The first time I saw Vikram Sarabhai was in Pune, in 1950. He and Homi Bhabha were giving lectures at the Indian Science Congress, and I was quite impressed by their presentations. I was a student of Physics then. In my Masters, I specialized in Electronics. Since the syllabus for M Sc Wireless was oriented primarily to theory, to make up, we were encouraged to do a Diploma in Electronics. In the Diploma course, we were exposed to the most recent laboratory instruments and procedures. So after my Masters from Pune University, when I went for an interview at ATIRA, the Ahmedabad Textile Industry's Research Association, for a post related to electronics, I had the advantage of hands-on experience. I was selected by the committee and finally interviewed by Vikram Sarabhai, Director of ATIRA. I asked him if I could work at the Physical Research Laboratory (PRL) while I was employed by ATIRA. My real desire was to work at PRL. He said, if that was the case, I had to meet K. R. Ramanathan, the Director of PRL, and he organized a meeting for me.

Ramanathan, when he met me, asked me why I was there. I told him that I was there because he was there. We were expecting him to take over the post of Head of the Department of Physics at Pune University after retiring from the India Meteorological Department and I was hoping to do research under him. But, unfortunately for us, in the meanwhile, Vikram Sarabahai had offered him the post of Director at PRL.

Ramanathan did not agree to my joining ATIRA and doing part time work at PRL. He told me that he could not offer me any scholarship for the moment, but that, within a few months, he might be able to arrange some finances. So I taught Physics at a college for a semester and then joined PRL for research with a scholarship of 100 rupees per month. Meanwhile, I had an offer from UPSC to join All India Radio. Though that had a much higher salary, I joined PRL instead. That was 1953. Vikram Sarabhai remembered that and mentioned it a few years later, to explain my ignoring the offer of a post at MIT.

PRL was then a small set-up at the M.G. Science Institute. Ramanathan occupied one small room. Then there

*As told to K. P. Madhu, Science Writing Consultant

scienceandmediaworkshops@gmail.com were three college classrooms and a connecting corridor. One had a small library and a row of benches for lectures. In another, three of us researchers were given a table and two chairs - which meant that at least one of us should be working at the lab, while two of us sat.

Vikram Sarabhai had a table and chair at the end of the corridor. So whenever Sarabahai was not there, we would occupy his table. Sarabhai would come in the morning at about 8, and work at PRL till about 10.30 and then go to ATIRA. He would go home for lunch and then till about five in the evening, he would attend to his other businesses. At about $5 \mathrm{pm}$, he would come back and work in PRL till about 8.30. This gave us a role model, to work without thinking about office hours.

PRL was poor those days in terms of funding. But because of Sarabhai, we had many visitors. Krishnan from NPL would come for lectures. P. M. S. Blackett from Cambridge would come often. Once, four people came and Vikram Sarabhai told me: 'Chitnis, explain to them what we are doing here'. Three of them were Nobel Prize winners. And the fourth was Chandrasekhar, who got the Nobel later. So, though we were poor, we had the richest of inputs at PRL because of Sarabhai, Linus Pauling, Hannes Alfvén...

We had a lot of freedom to dream big and the motivation to work hard to achieve those dreams. I developed the Geiger counter, Cherenkov counter, scintillation counters, etc. And we got a project, along with Bruno Rossi in MIT, to set up instrumentation at Kodaikanal, to detect particle showers and to provide clues about the direction from where they were coming.

Kodaikanal had the most interesting weather pattern. It would be clear in the morning. Then it would cloud over on most days and, by afternoon, it would rain. It would clear up quickly and the nights were always very clear. I have never seen the moon so bright anywhere else. With such clear skies, we accumulated a lot of data. Rossi was happy and offered me a position at MIT. I did not reply. After a few weeks, Rossi told Sarabahai. And when Sarabhai met me, he asked me. I told him that the project would take two more years and that I would think about the position at MIT later.

But we had accumulated a lot of data and it was impossible to make sense of it without adequate computation power, which we did not have in India at that time. 
So ultimately, I went and joined MIT to work with Rossi in 1957.

This was a time when the US was overhauling its science education. Textbooks were being revised; new experiments were being included in the curriculum. One of the main people involved used to sit one floor below where I worked. When Sarabhai came to visit MIT, he collected some of the experiments, took them to PRL and started the Community Science Centre. Later, it was shifted to a museum, before the Centre got its own land and building. As an institution builder, this was his consistent strategy: dream big and not hesitate to start, however small.

Meanwhile, the intellectual freedom and the work culture at MIT influenced me greatly. I adapted quickly and enjoyed my work. So time passed quickly. And then Vikram Sarabhai contacted me and asked me to join the Space Application Centre.

People at MIT found it amusing for a country like India in the early 1960s to get into space research. Our aim was not to conquer space, but to overcome underdevelopment and poverty on the ground, using space technologies. Vikram Sarabhai argued that the experimental earth station for satellite communication set up in Ahmedabad would help not only India, but would work as a training ground for the other countries in the region. Thus he could secure funding from UNDP.

I left MIT to join the Space Applications Centre (SAC). My wife also had to leave her job. So we were back at PRL. PRL had a new two-storey building by then and SAC started operations there - the usual two-fold strategy of Sarabhai: 'thin end of the wedge' and 'sudden expansion', as he used to say. Thus PRL became the cradle of space science in India.

By this time, quite a few had gone from PRL to not only MIT, but also to Cambridge, Stanford and other places - Canada, France.... Most of them came back. There were people from different parts of India, with exposure to research and contacts in different parts of the world - factors that played a role in the success stories that followed.

People came back leaving their well-paid jobs abroad because of Sarabhai. He was kind and compassionate. Even a peon could walk into his room with grievances and grumbles. And people who came out of his room were always smiling.

He was egalitarian. He would introduce his colleagues to the foreign visitors as if they were equal. While Dr Ramanathan followed C. V. Raman's attitude to women and scientists less brilliant, Sarabhai was humane. Though he was not really an artist like Bhabha was, he appreciated art forms and respected Mrinalini, his wife enough to help set up the Darpana Academy of Performing Arts.

He could judge others' capabilities, delegate responsibilities and give full freedom and trust people to perform to the best of their abilities. So, the first earth station in India was soon set up in Ahmedabad. And it became the training ground for engineers in not only India, but also for those in the African and other Asian countries.

Meanwhile, Sarabhai's 'thin edge strategy' was working in another direction. Between the regions where satellites are and the regions of atmosphere that can be explored with balloons, there is a big gap. That was to be explored using sounding rockets. Most of the sounding rockets those days were in the polar and temperate zones. And we felt that one near the magnetic equator would be useful to explore the equatorial electrojet. So I was asked to look into it.

Though the magnetic equator passed south of what is now Kollam, Thumba was identified as the best location, with minimum disturbance to local population. To finalize the decisions, we were to meet the Governor, V. V. Giri. We, including Bhabha, reached early and were accommodated at his residence. But Sarabhai arrived late. When he reached, the introductions to Giri's friend, Raghu and Raghu's wife, a Swedish citizen, were already over. So Bhabha played the gentleman and tried to introduce Raghu and his wife. Before he could start, Sarabhai said, 'Oh, Raghu, how nice to meet you again', shook his hand and kissed his wife's cheek, European fashion.

I still have to see anybody who needs to be introduced to Vikram Sarabhai. He knew people. And he knew how to deal with them.

$\mathrm{He}$ got what he wanted from other countries also. $\mathrm{He}$ convinced decision makers in other countries that India could deliver. We got a helicopter from Russia to monitor the sea and to ensure the safety of fishermen when the sounding rockets were launched along with a computer and the vibration table for testing the components. Though we used American-made rockets initially, we had to buy the rockets and the technology from the French and we soon started making rockets indigenously. Hideo Itokawa, the Japanese contact that I had, helped in improving the rocket design. This is how the 'sudden expansion' strategy of Sarabhai worked.

Meanwhile, many people complained about the location. Thumba, and even Trivandrum of those days, were considered too backward to attract scientists to come and stay. That was one time that I saw Sarabhai putting his foot down. He put an end to the discussion. The location, though it was not too convenient, was important from the point of view of international collaboration in scientific research. He even got Indira Gandhi to dedicate Thumba to the UN. Sounding rockets of the US, Germany, France, Russia and Japan were launched from there.

We had access to the skies of the southern hemisphere from Thumba. And, since we carried X-ray detectors in some of the rockets, we found a large number of X-ray sources. Though the experiment was to check possible $\mathrm{X}$-ray emissions from the moon, which we did not find, 
these findings kicked off the discipline of X-ray astronomy. The International Union of Geodesy and Geophysics and the Space Shuttle Mission of the US took India seriously because of this commitment to space science.

I remember a meeting with $\mathrm{H}$. G. S. Murthy, the Director of Thumba who was enlarging his team, coming to Sarabhai with a problem. He had one post, but two very good candidates. He would have liked to offer jobs to both. We were sitting in a hotel in Boston. Sarabhai pushed the biodata of the second candidate over to me and asked my opinion. It was Kalam's. Given the way he managed to grow from his poor circumstances, I also recommended that he be taken in. Later, Sarabhai would smilingly refer to Kalam as busy bee. Whenever Sarabhai would go for a meeting in Thumba, Kalam would come up with many new projects for approval.

It is not only people. Sarabhai had the ability to anticipate and to make use of what he had. So we had received this computer, IBM.... And he got people trained to operate it. The computer was on 23 hours a day, leaving one hour for maintenance. It would work on SAC projects for eight hours and, the rest of the time, other things could be done. So we were soon making money by handling the payrolls of large corporations like ONGC. Meanwhile, another computer which was delivered to the Department of Atomic Energy was still lying in its crate.

Bhabha who was spearheading the Atomic Energy Commission was frustrated by the bureaucratic processes and promised Sarabhai a more convenient constitution for ISRO. But unfortunately, before that could materialize, the plane carrying Bhabha was crashed. So ultimately Atomic Energy and ISRO had a similar constitution: the Finance Secretary is the Member Finance and the budget that is approved in the Commission is binding.

Sarabhai knew how to anticipate and overcome obstacles. He convinced Morarji Desai to induct a renowned economist as the Secretary Finance to get his way around the bureaucratic impedance and to get the projects going - a trick that Bhabha could not envisage.

Sarabhai was a businessman. He knew how to negotiate, how to leverage on existing contacts, how to overcome bureaucratic barriers. By close observations, we, the engineers and scientists, also imbibed his ways and benefited from them, later.

I was asked to find a site for a launching station. Sarabhai asked me to take along Abid Hussain from Madras, as Chennai was called those days. He had the right con- tacts and commanded respect among the bureaucracy. But I could not get time from him. So I had to go on my own and explain the requirements to the bureaucrats - a place near the sea, unoccupied acreage, safety for local population...

I had surveyed the coasts in Tamil Nadu. But Tamil Nadu was too near Sri Lanka and we did not want any trouble with neighbours. Sriharikota in Andhra Pradesh seemed to be the best location. Abid Ali, the bureaucrat that I had to deal with, was from the Nizam's rule. He did not understand our purpose nor cared. So to clinch the deal, Abid Hussain from Madras came with me to convince him. And Bhrahmananda Reddy, of the Andhra Pradesh Government, gave us an island of 40,000 acres, free of cost.

The way Vikram Sarabahai conceptualized the SITE project is the most telling example of his negotiation skills. The telecommunication people those days did not feel the need for a satellite. But to achieve all India coverage for television using the technologies of those days would have taken about half a century or more. Satellites could achieve it, in a much shorter time and with onetenth the costs.

That was a time when we did not have much foreign exchange. Sarabhai knew he could not buy things from abroad for the project with foreign currency. So he organized the project such that there was no transfer of money. We would spend money on behalf of the Americans and the Americans would spend money on our behalf. And all parties kept detailed accounts to cancel each other's expenses. His business and financial acumen kept the project on track.

We should not forget that he came from a business community that could envisage a port in Ahmedabad for easing their shipping problems. But he was also a scientist and a humanist. So his vision went further than taking commercial products to the Arabian Sea: he envisioned an ISRO that could put satellites in space.

Sarabhai, of course, could not see the SITE project take shape and become an internationally acclaimed communication project. He passed away peacefully in his sleep, a few years before the SITE experiment. But because of his vision, space science in India has firm roots in Indian soil, and plays a central role in communication, meteorology, agriculture, land-use planning, disaster detection, monitoring....

doi: $10.18520 / \mathrm{cs} / \mathrm{v} 118 / \mathrm{i} / 1177-1179$ 